\title{
Casting Ballots When Knowing Results
}

\author{
Victor Araújo ${ }^{1 *}$ (D) and Malu A.C. Gatto ${ }^{2}$ \\ ${ }^{1}$ University of Zurich, Switzerland and ${ }^{2}$ University College London, UK \\ *Corresponding author. Email: victor.araujo@pw.uzh.ch
}

(Received 2 June 2020; revised 7 April 2021; accepted 9 June 2021)

\begin{abstract}
Access to information about candidates' performance has long stood as a key factor shaping voter behaviour, but establishing how it impacts behaviour in real-world settings has remained challenging. In the 2018 Brazilian presidential elections, unpredictable technical glitches caused by the implementation of biometrics as a form of identification led some voters to cast ballots after official tallies started being announced. In addition to providing a source of exogenous variation of information exposure, run-off elections also enable us to distinguish between different mechanisms underlying the impact of information exposure. We find strong support for a vote-switching bandwagon effect: information exposure motivates voters to abandon losing candidates and switch support for the frontrunner - a finding that stands in the second round, when only two candidates compete against each other. These findings provide theoretical nuance and stronger empirical support for the mechanisms underpinning the impact of information exposure on voter behaviour.
\end{abstract}

Keywords: voter behaviour; bandwagon effect; underdog effect; strategic voting; natural experiment; Brazil

First, it's absurd, right? Queuing for four hours to vote. But I think the worst part was to vote knowing about the results. Man, I got desperate.... Everyone was desperate, without knowing what to do, who to vote for.... Like, I swear, I was shaking when voting. I was shaking. It was 10 minutes of desperation. Everyone talking to me on Instagram. How come Bolsonaro will win in the first round [of elections]? Like, [he has] 49 per cent [of the votes], for Christ's sake. Seriously, it was exasperating.

The preceding quote is how a Brazilian voter described her state of mind in a WhatsApp audio message $^{1}$ while waiting in the queue to vote in the 2018 presidential elections. Her description is aligned with questions political scientists have asked for decades: does information about candidates' electoral performances impact voters' decisions?

Many studies argue that, yes, learning about candidates' electoral prospects - either through polls or earlier electoral results - impacts voters' behaviour. But how? One possible explanation is that information exposure changes voters' participation levels in ways that increase the frontrunner's lead over losing candidates, resulting in an observed 'bandwagon effect' (see, for example, Agranov et al. 2018; Dubois 1983; Gartner 1976; Morton et al. 2015). Another possibility is that learning about candidates' performances leads some voters to abandon predicted losers and switch support to the frontrunner (see, for example, Bischoff and Egbert 2013; Evrenk and

\footnotetext{
${ }^{1}$ This was personally acquired by the authors on 7 October 2018, has been translated from Portuguese and is reproduced here with written consent.

(c) The Author(s), 2021. Published by Cambridge University Press. This is an Open Access article, distributed under the terms of the Creative Commons Attribution-NonCommercial-NoDerivatives licence (http://creativecommons.org/licenses/by-nc-nd/4.0/), which permits noncommercial re-use, distribution, and reproduction in any medium, provided the original work is unaltered and is properly cited. The written permission of Cambridge University Press must be obtained for commercial re-use or in order to create a derivative work.
} 
Sher 2015; Gallup and Rae 1940). Information exposure may also prompt voters to adjust their preferences strategically inn order to avoid a less-preferred outcome; in some instances, these strategic calculations could also increase the frontrunner's advantage over other candidates (see, for example, Cox 1997; Eggers and Vivyan 2020; Kawai and Watanabe 2013).

Although theoretically different, in naturally occurring elections, the empirical outcomes of these mechanisms are often observationally equivalent (Barnfield 2019; Chung, Heo and Moon 2018; Evrenk and Sher 2015). As such, many existing studies on the impact of information exposure on voter behaviour have relied on survey or laboratory experiments seeking to replicate electoral conditions (see, for example, Agranov et al. 2018; Bischoff and Egbert 2013; Farjam 2020; Fleitas 1971; Morton and $\mathrm{Ou}$ 2015). In the current article, we exploit a unique source of exogenous variation to examine whether exposure to information impacts voters' behaviour in a real election; in so doing, we provide more fine-grained causal and theoretical assessments than previous studies.

In 2018, for the first time in Brazilian history, fingerprints were used as the main form of identification (ID) for 73.6 million voters - more than half of the electorate of 147.3 million people. Technical glitches associated with the use of the newly introduced biometric ID technology caused delays in voting processes, leading some voters to cast ballots after the release of the first official vote tallies. In other words, variation in delays in some polling stations meant that some voters cast ballots under different conditions of exposure to partial results. Using timestamp data of the last vote cast in each voting machine $(\mathrm{N}=454,490)$, we identify the places where voters were still casting ballots after electoral results started being announced. This allows us to examine whether gaining knowledge of the results affects support for the predicted winning and losing candidates.

In addition to this empirical opportunity, the institutional set-up of Brazilian presidential elections also enables us to get past the equifinality and to not only estimate the impact of information exposure on voter behaviour, but also locate the mechanism driving the observed effects. Specifically, the setting allows us to account for mobilization and candidate support rates, as well as to examine the impact of information exposure on voter behaviour under two scenarios: in the first round, when there are various candidates competing and strategic voting is possible; and in the second round, when only two candidates compete for the majority of votes and strategic vote switching is not possible.

With data from the first round of elections, in which 8,548 (1.6 per cent) of voting machines were 'treated' as a result of technical glitches, we find support for the explanation that access to information about candidates' electoral performances leads to a bandwagon effect through conversion. Specifically, we find that exposure to electoral results increased support for the frontrunner by 5.69 percentage points (pp) and decreased support for the second and third runners-up by $7.41 \mathrm{pp}$ and $1.97 \mathrm{pp}$, respectively.

As there are more than two candidates competing in the first round, however, these observed effects could have been the product of strategic voting. Employing data from the second round of elections, in which technical glitches resulted in 1,024 (0.24 per cent) of machines remaining open past the time of announcement, we find that when only two candidates competed for the majority of votes, information exposure still resulted in a $11.76 \mathrm{pp}$ increase in support for the predicted winner and a $12.14 \mathrm{pp}$ loss for the predicted loser. This confirms that information exposure benefited the frontrunner through a vote-switching (that is, conversion) bandwagon effect, not strategic voting.

A series of alternative model specifications provide further robustness to our findings. Notably, in analyses with data from the previous 2014 elections, we show that treated units were not in constituencies already more prone to supporting the frontrunner. In addition, in placebo tests, we show that our results cannot be explained by voters' experience of waiting in the queue alone: bandwagon effects only emerge in units where voters were still casting ballots after the threshold of exposure to electoral results.

Our findings show that gaining knowledge of a candidate's lead can convert voters' support in their favour, even in the unlikely context of a highly polarized, high-stakes election. These 
findings have normative implications: in free and fair elections, every vote should count equally, but because it prompts a bandwagon effect, exposure to information gives greater weight to early voters' preferences.

\section{Information Exposure and Voter Behaviour}

Since Duverger (1954), generations of political scientists have sought to better understand the factors that shape voter decisions. Access to information has since stood as a key factor: even when candidate options and voters' ideological preferences are taken as given, evaluations of candidates' electoral prospects may still impact voters' choices (Downs 1957; Gartner 1976) - even if voters themselves underestimate the impact of information on their behaviours (Chung, Heo and Moon 2018).

Voters can attain information about candidates' electoral prospects through various means. Most commonly, this happens through pre-electoral polls (Hardmeier 2008; Moy and Rinke 2012; Schmitt-Beck 1996). Electoral rules that make elections sequential, such as primaries or run-offs, also give voters knowledge about candidates' performances in a first race, allowing them to make estimations about candidates' electoral potential in subsequent races (Bartels 1988; Morton and Williams 1999).

Increasingly, however, new information about candidates' electoral prospects - via leaked exit polls, for example - emerge while elections are taking place and voters can still cast ballots (Morton et al. 2015). These instances are different from those previously mentioned in significant ways: first, these are cases of otherwise simultaneous elections that only become sequential as a result of the unanticipated dissemination of information; and, second, the information released in these circumstances is more precise than in the aforementioned ones and reveal the actual choices of early voters.

Historically, scenarios prompting sequential voting in technically simultaneous elections have been more common in countries with multiple time zones, where polls close in some parts of the country while remaining open in others. The 1980 US presidential race is perhaps the most notorious: Carter conceded to Reagan based on media coverage of East Coast results, but polls had not yet closed in the West - something that has also been associated with lower turnout and support rates for Democrats in Western congressional races (see, for example, Carpini 1984; Dubois 1983). ${ }^{2}$

Despite similar recurring occurrences in the US and elsewhere since, the scholarship remains inconclusive about the direction and underlying mechanisms of the impact of information exposure on voter behaviour. According to some, access to information about candidates' prospects results in a bandwagon effect by encouraging conversion, that is, vote-switching away from predicted losers and in favour of the frontrunner (see, for example, Bischoff and Egbert 2013; Evrenk and Sher 2015; Gallup and Rae 1940; Kenney and Rice 1994; McAllister and Studlar 1991). This effect could be driven by various types of psychological motivations, including: late voters' use of early voters' preferences as a heuristic for candidates' competence; individuals' desire to be associated with winners; or altruism (Barnfield 2019; Morton and Ou 2015; Moy and Rinke 2012).

Others have argued that voters do not change their preferences, but, instead, are more likely to undergo the cost of voting if their preferred candidate is expected to win. Conversely, learning about their preferred candidates' predicted losses could demobilize voters and result in lower turnout rates among supporters of the trailing candidate (see, for example, Agranov et al. 2018; Duffy and Tavits 2008; Grillo 2017; Großer and Schram 2010; Morton et al. 2015). While these mechanisms are distinct, their observable aggregate outcomes would be the same, making it difficult to disentangle them.

Instead of a bandwagon effect, information exposure could also prompt the opposite: an 'underdog effect' - a less common prospect (Hardmeier 2008) that seems to be more likely in

\footnotetext{
${ }^{2}$ Some scholars have challenged these findings based on data quality and model specifications (see Morton et al. 2015).
} 
non-competitive elections (Chatterjee and Kamal 2020). Similarly to a bandwagon effect, the underlying mechanisms underpinning higher rates of support for the trailing candidate could also emerge from vote switching or changes in mobilization rates.

In addition, information exposure could also prompt 'strategic voting'. While definitions vary, strategic voting generally refers to processes whereby access to new information about candidates' electoral prospects leads voters to adapt their strategies (Cox 1997). In these instances, voters may choose to forgo casting a ballot for their favourite choice and support an alternative candidate when doing so could avoid a less-preferred outcome (see, for example, Alvarez and Nagler 2000; Blais et al. 2011; Heath and Evans 1994; Kawai and Watanabe 2013).

Unlike bandwagon/underdog effects, strategic voting does not predict vote switching for a specific winner/trailing candidate. As such, the observable effects of strategic voting can vary and are not always distinguishable from those of bandwagon/underdog effects (Evrenk and Sher 2015; Riambau 2015). For example, in the scenario proposed by Eggers and Vivyan $(2020,478)$ in which a voter 'is nearly indifferent between the two frontrunners and strongly opposed to the third-place candidate, [and] she is best off with an insincere vote [for the frontrunner]', the aggregate outcome of strategic voting would be observably indistinguishable to that of a bandwagon effect.

In sum, while the scholarship has found plentiful evidence that access to information meaningfully impacts voter behaviour, disentangling the mechanisms underlying observable aggregate outcomes of information exposure on voter behaviour is most often not possible (Barnfield 2019; Chung, Heo and Moon 2018; Evrenk and Sher 2015). To address some of the methodological challenges faced by research employing data from naturally occurring settings (see, for example, Chatterjee and Kamal 2020; McAllister and Studlar 1991; Morton et al. 2015; Riambau 2015), many studies have relied on survey or laboratory experiments seeking to replicate electoral conditions (see, for example, Agranov et al. 2018; Bischoff and Egbert 2013; Farjam 2020; Fleitas 1971; Morton and Ou 2015). While these methods improve causal estimations and enable researchers to better disentangle mechanisms, the approaches yield low external validity: simulations tend to take place in unrealistic settings that cannot replicate the stakes of elections and are most commonly carried out among homogeneous groups of participants. As we detail next, the 2018 Brazilian election provides a unique natural experimental setting, as well as an ideal institutional set-up that allows us to distinguish between different explanations of the impact of information exposure on voter behaviour.

\section{The Case of Brazil}

The 2018 Brazilian presidential elections took place during contentious times, following the impeachment of Dilma Rousseff in 2016 and growing levels of voter distrust in political parties and elites (Hunter and Power 2019). With 35 registered parties, 28 of which attained congressional seats in the 2014 elections, Brazil stands as one of the most highly fragmented party systems in the world (Power and Rodrigues-Silveira 2019). Despite high party fragmentation, recent democratic history indicated the stability of a bipartisan norm in presidential races, with candidates from the centre-left Partido dos Trabalhadores (Worker's Party [PT]) and centre-right Partido da Social Democracia Brasileira (Brazilian Social Democratic Party [PSDB]) generally competing for the country's highest office (Samuels and Zucco 2018).

In the months preceding the elections, increasing levels of polarization showed signs that the PT versus PSDB race would not repeat itself in 2018. Polls suggested the PSDB candidate, Geraldo Alckmin, to be highly unpopular; meanwhile, the imprisonment of the PT's leader, former president Luiz Inácio Lula da Silva, meant that he had to be substituted for Fernando Haddad, a name that did not inspire voters to regain trust in the party (Hunter and Power 2019).

At the same time, the growing popularity of far-right candidate Jair Bolsonaro, from Partido Social Liberal (Social Liberal Party [PSL]) - a party that had secured only one seat in the Chamber 
of Deputies just four years prior - indicated voters' support for new leadership. While Bolsonaro and Haddad maintained the lead throughout the electoral campaign, they also retained the highest levels of voter rejection. This meant that for many voters, keeping Bolsonaro or Haddad (that is, the PT) out of office was the main goal (Rennó 2020).

High rates of rejection of the top two frontrunners provided the opportunity for other candidates to campaign as better alternatives to Bolsonaro and Haddad. As the election day approached, the centre-leftist Ciro Gomes, from Partido Democrático Trabalhista (Democratic Labour Party [PDT]), took the lead as the most electorally viable third option.

In the first round of elections, if none of the candidates is able to attain 50 per cent (plus one) of the valid votes, the two candidates that receive the most votes compete in a second round. Although majoritarian in nature, the first round of elections thus grant voters the opportunity to signal their ideological preferences by casting a vote for a candidate closer to their ideological preferences - as a consequence, increasing the number of competitive candidates (Fujiwara 2011; Guarnieri 2015; Plutowski, Weitz-Shapiro and Winters 2020). In this second round, the candidate who secures the majority of the national votes wins.

The two rounds allow us to examine the impact of information exposure on voter behaviour in one race with multiple candidates and a second with only two candidates - and thus to assess whether information exposure impacts voter behaviour in a scenario in which strategic voting is not possible. Critically, the highly polarized context of the 2018 Brazilian elections means bot only that the first round of elections is a 'most likely' case for the impact of information exposure on voter behaviour, but also that the second round between Haddad and Bolsonaro - diametrically opposed candidates - presents a 'least likely' scenario (Levy 2008) for behavioural change, and thus a hard test for existing explanations of the impact of information on voter behaviour (Gartner 1976).

Finally, the Brazilian case also offers granular data that allow us to distinguish between mechanisms driven by changes in mobilization and those prompted by vote switching. This is because in addition to casting ballots for specific candidates and parties, Brazilian voters can also display demobilization by casting blank or null ballots - options generally employed by those who are undecided, find all candidates inadequate or choose to cast a protest vote (Zucco and Nicolau 2016). ${ }^{3}$ In addition, efforts to monitor compliance with compulsory voting also mean that we have precise information about the number of voters who did and did not turn up to vote. However, although voting is compulsory, the penalty for not voting is a small fine of $\mathrm{R}$ $\$ 3.51$ (US\$0.90), ${ }^{4}$ so abstention remains an option (Cepaluni and Hidalgo 2016). In fact, an average of 20 per cent of voters do not vote at each electoral cycle (Power 2009), rates that are similar to those from countries with non-compulsory voting, such as Sweden, South Korea and New Zealand (Hutt 2018). In the 2018 elections, the turnout rate was 79.95 per cent in the first round and 78.84 per cent in the second round.

\section{Information Exposure and the Biometric System}

Technical glitches that occurred in the 2018 elections also allow us to exploit a clear threshold of exposure to information about electoral results. Brazilian electoral regulation establishes that polls officially close at 17:00 local time. Due to being home to three time zones, regulations stipulate that vote tallies can only start being released after the polls officially close in the last time zone, that is, Zone 5 (encompassing the state of Acre and a small portion of Amazonas state). In practice, this regulation is meant to protect voters in all time zones from gaining knowledge about other regions' electoral preferences.

Severe delays in voting have traditionally been an unlikely prospect: in Brazil's modern democratic history, a number of electoral institutions have been put in place to facilitate the exercise of

\footnotetext{
${ }^{3}$ Null votes can sometimes also result from voters' inadvertent mistakes (Zucco and Nicolau 2016).

${ }^{4}$ On 8 October 2018, the day after the first round of the elections, the R\$/US\$ exchange rate was 3.894 .
} 
compulsory voting. Setting elections for a Sunday, assigning voters to electoral stations close to their registered residencies, limiting the number of voters per assigned polling station and digitizing the voting experience through the use of electronic machines have generally meant that voting in Brazil is not a time-consuming affair (Nicolau 2012).

Put differently, regulation establishing that the release of official results could only begin after the closing of polls in Zone 5 worked well in the past: elections were carried out efficiently, and one- and two-hour differences across time zones ensured that voters from other regions of the country were done casting ballots before the official closing of elections in Zone 5, when the release of vote tallies began.

This was not the case in 2018. On this occasion, the use of fingerprints as a form of ID became mandatory for 73.6 million voters from 2,793 Brazilian municipalities (50.3 per cent of the electorate). The system was also available (but not mandatory) in another 1,533 municipalities, thus covering a total of 77.7 per cent of municipalities and 59 per cent of the electorate. While the innovation did not cause disturbances in some voting stations, technical problems related to the identification of voters using fingerprint readers caused considerable delays in many others.

As explained by Giuseppe Dutra Janino, Head of the Secretariat for Information Technology of the Tribunal Superior Eleitoral (Superior Electoral Tribunal [TSE]), technical errors happened when there were physical problems with the machines ${ }^{5}$ or, more often, when reading voters' fingerprints took more than one try - a problem that emerged not only due to staff misplacing voters' fingers on the machines, but also from the inappropriate collection of biometric data in the period preceding the election (Clavery 2018). To expedite the use of biometrics as a form of voter ID, the TSE operated a data-sharing scheme with other government institutions. As such, the collection of voters' fingerprints was completed not only by electoral authorities, but also by other government authorities that issue ID cards (such as state transit departments), whose main objective when collecting fingerprints is not their use as a form of ID (Mendonça and Albernaz 2018).

As Figure 1 shows, technical problems that resulted from the use of biometrics meant that voters assigned to stations employing the system were significantly more likely to face delays and vote after 19:00 Brasília time (BRT), ${ }^{6}$ when the TSE officially started disseminating vote tallies. Consequently, voters who cast ballots after the election's official closing time were plausibly better informed about predicted electoral outcomes than those who voted earlier.?

The rapid announcement of results and the vast employment of communication tools for political purposes in Brazil make it highly plausible that individuals still waiting in the queue at 19:00 BRT would have quickly become knowledgeable about early voters' preferences. First, the use of electronic voting machines means that electoral results are calculated speedily and start being publicly released immediately after the official closing time of polls in Zone 5. For example, in the first round of elections, when vote tallies started being released at 19:00 BRT, more than 65 million votes (44 per cent of total votes) had already been counted (Grandin et al. 2018). Additionally, roughly 60 per cent of Brazilian adults own smartphones, and Brazil currently ranks third in the world in respect to the number of hours spent using communication apps (Lopez 2019). Critically, 99 per cent of smartphone users in Brazil communicate via WhatsApp - a tool that was key for the rapid dissemination of political information in the 2018 elections (Mello 2020).

\footnotetext{
${ }^{5}$ For more information on the machine used for fingerprint reading, see Online Appendix A.

${ }^{6}$ One concern in our setting is that the implementation of the biometric system correlates with state capacity. In this case, we should expect a higher concentration of biometric voters in Brazil's wealthiest states. As Online Appendix B shows, this is not the case.

${ }^{7}$ 'Official closing time' refers to established election hours, not the time of the last vote cast in a given machine. Voters who arrive at their assigned voting stations before their closing times can remain in queue and are guaranteed their right to cast a ballot. As such, the actual (i.e., recorded) time of closure of specific voting machines can be considerably later than their 'official closing time'.
} 


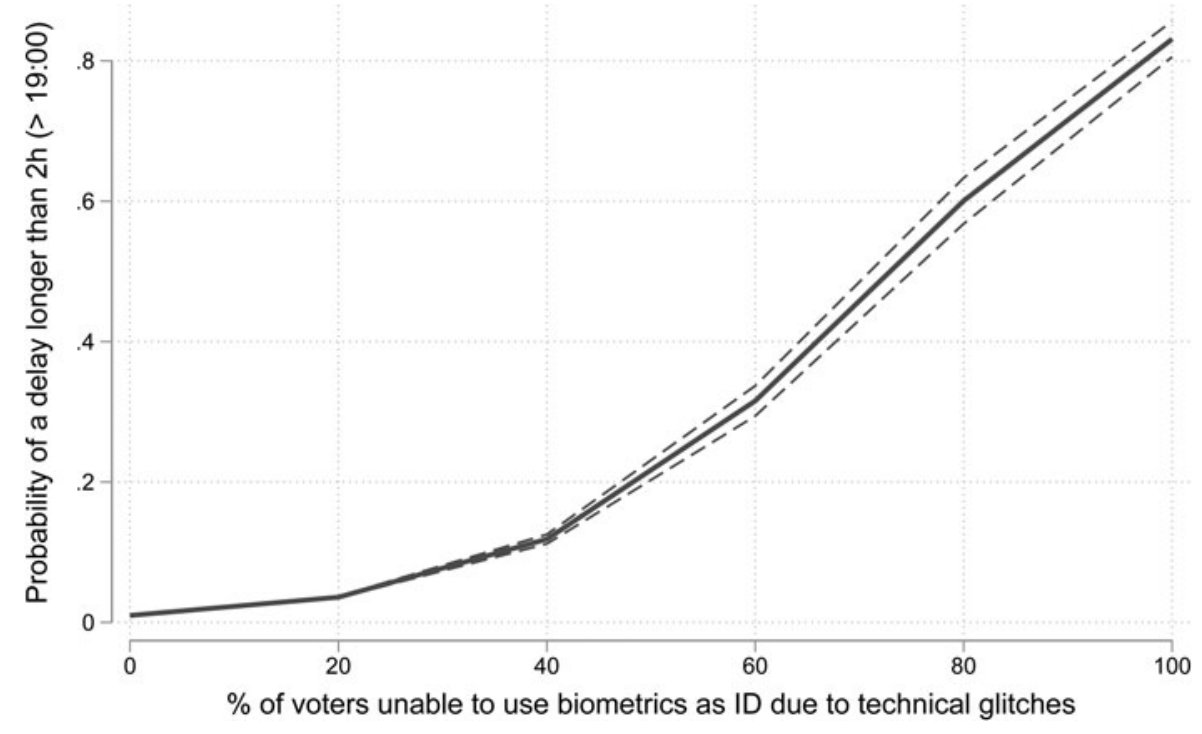

Fig. 1. Probability of being exposed to information in the first round of the 2018 Brazilian elections. Notes: The unit of analysis is voting machine $(\mathrm{N}=453,319)$. We cluster standard errors at the level of voting machine (where the treatment took place). We run all logit estimates with controls for turnout rate, age (avg.), percentage of women voters and years of schooling (avg.). All graphs in this article were produced using the plotplain developed by Bischof (2017).

When the results started being announced, Bolsonaro had 48.83 per cent of the counted votes, just 1.17 per cent short of reaching the 50 per cent (plus one vote) required to win on the first round. The second runner-up, the PT's Fernando Haddad, came 22.75 pp behind, with 26.08 per cent of the votes, and the third runner-up, PDT's Ciro Gomes, had 12.50 per cent of the votes. Throughout the counting (and announcement) of votes, Bolsonaro led by a wide margin of at least $16.45 \mathrm{pp}$ (Grandin et al. 2018). In the second round, when results started being announced at 19:00 BRT, Bolsonaro had 55.7 per cent of the votes and an 11.4 pp lead over Haddad (G1 2018).

\section{Hypotheses}

By examining the share of ballots cast for specific candidates, as well as blank and null votes, we can identify and better disentangle the two underlying mechanisms of a bandwagon or an underdog effect; meanwhile, by comparing voters' behaviour in the first and second rounds of the elections, we can differentiate between bandwagon/underdog effects and strategic voting. Formally, our case and empirical strategy allow us to test five different hypothesized scenarios:

Hypothesis 1: Access to information induces a bandwagon effect by demobilizing voters who would otherwise support predicted losers (demobilizing bandwagon effect).

Since it is not possible to capture this at the individual level (due to secret ballots), if this mechanism is in place, we should observe no changes in the vote share of the predicted winner (Bolsonaro), but drops in the vote shares of the predicted losers (Haddad, the second-place candidate, and Gomes, the third-place candidate in the first round) and higher shares of blank and null votes.

In theory, it is also plausible that a demobilizing bandwagon effect could emerge from differential rates of turnout, whereby voters who would have otherwise abstained would become motivated to support the frontrunner, while supporters of losing candidates would be more likely to 
withdraw their participation in the election. In the 2018 Brazilian elections, however, only the latter was possible.

Information exposure was a product of technical glitches and only affected voters still in queue after their voting stations' official closing times. As per Brazilian electoral law, individuals who arrive after the station's official closing time are banned from entering voting stations and casting ballots, but voters who are already in queue to vote at a polling station's official closing time can still cast ballots. As such, in the 2018 elections, information exposure could only change turnout rates by prompting voters already in the queue to withdraw. As we further detail in our empirical strategy, we account for this by controlling for turnout rates in all of our estimates:

Hypothesis 2: Access to information induces a bandwagon effect by prompting voters to abandon the predicted loser and switch votes to the frontrunner (vote-switching bandwagon effect).

Observably, this would mean that exposure to information should result in a higher vote share for the predicted winner (Bolsonaro), lower vote shares for his losing competitors - Haddad (second place) and Gomes (third place in the first round) - and no changes in the shares on blank and null votes:

Hypothesis 3: Access to information induces an underdog effect by mobilizing voters who would otherwise abstain to support the predicted loser (mobilizing underdog effect).

If information exposure drives an underdog effect through mobilization, then we should observe no change in the vote shares of the predicted winner (Bolsonaro) or second-place candidate (Haddad), but an increase in the vote shares of the third-place candidate (Gomes) ${ }^{8}$ and lower shares of blank and null votes ${ }^{9}$ :

Hypothesis 4: Access to information induces an underdog effect by prompting voters to abandon other candidates and switch votes to the predicted loser (vote-switching underdog effect).

Observably, this would result in a decrease in the vote shares of at least one of the two top contenders (Bolsonaro and/or Haddad), an increase in the vote share of the trailing candidate (Gomes) and no change in the shares of blank and null votes.

HyPOTHESIS 5: Access to information induces strategic vote switching (strategic voting).

Unlike expectations about bandwagon and underdog effects, strategic voting does not yield a single possible outcome and is shaped by voters' electoral preferences and less-preferred choices. Accordingly, in the first round of the 2018 Brazilian elections, strategic voting could yield a number of distinct outcomes. First, upon learning about Bolsonaro's lead, his sincere voters should not change their behaviour. The supporters of Haddad (second place) should also not change their behaviour in an attempt to ensure that Bolsonaro does not achieve the 50 per cent (plus one) threshold of votes that would win him the presidency in the first round.

\footnotetext{
${ }^{8}$ We restrict our analyses to the first three most popular candidates, instead of all 13 . As such, we consider the trailing candidate to be Gomes.

${ }^{9}$ As previously conveyed, in the case of the 2018 Brazilian elections, a mobilizing underdog effect could not be prompted by higher rates of turnout given that voters arriving at their voting stations after information exposure (i.e., stations' official closing times) would have been barred from entering.
} 
Meanwhile, upon learning that Gomes is in the third place and has no chance of moving to the second round, Gomes's supporters could vote strategically. If their less-preferred outcome is a Haddad win, then they should vote-switch to Bolsonaro. If their less-preferred outcome is a Bolsonaro win, then they could vote-switch to Haddad if they believe that doing so would strengthen Haddad's perceived viability and chances of winning in the second round. However, it is also possible that Gomes's supporters whose less-preferred outcome is a Bolsonaro win would not change their behaviour, as doing so would not directly help defeat Bolsonaro in the first round.

Since Gomes's supporters plausibly have heterogeneous preferences regarding their less-preferred choices, it is unclear how strategic voting should observably impact candidates' vote shares. If at least some of Gomes's supporters who engage in strategic voting prefer Bolsonaro to Haddad, however, then Bolsonaro's vote share should increase. In the first round of elections, this observable effect would be indistinguishable from a vote-switching bandwagon effect. In the second round, however, only two candidates compete and strategic voting is not possible, so an increase in Bolsonaro's vote share could only indicate a bandwagon effect.

\section{Empirical Strategy}

In the 2018 Brazilian elections, unpredictable technical glitches that resulted from the implementation of biometrics as a form of ID caused delays and led some voters to cast ballots after official tallies were already being announced. This exogenous source of information exposure, combined with information about the timing of the closure of voting machines and granular electoral data from the first and second rounds of the presidential elections, allow us to enhance causal estimations of the impact of information exposure on voter behaviour and disentangle its possible underlying mechanisms.

\section{Data}

In Brazil, citizens between the ages of 18 and $70^{10}$ are assigned to a specific voting zona ('zone'), local de votação ('voting place') and seção ('voting station'), which become their permanent voting assignment. ${ }^{11}$ A voting place could be a public school and a station could be a particular classroom within said public school where a voter would go to cast a ballot in every election. In each station, there is one voting machine - our unit of analysis. ${ }^{12}$ This set-up means that technical glitches associated with the implementation of biometrics took place at the level of voting machines, that is, in some cases, voters assigned to the same public school but different classrooms could have voted under different conditions of information exposure.

Official data are available for each round of the election for all 454,490 of Brazil's voting machines. ${ }^{13}$ On average, 323 voters are registered to cast ballots on each voting machine. With these data, we code five different outcome variables: (1) share of votes for Bolsonaro (frontrunner); (2) share of votes for Haddad (second place); (3) share of votes for Gomes (third place $^{14}$; (4) share of blank votes; and (5) share of null votes.

\footnotetext{
${ }^{10}$ Voting is optional for those between the ages of 16 and 18 or over 70.

${ }^{11}$ Unless they change domiciles or the electoral authorities redesign voting distributions (e.g., due to demographic growth).

${ }^{12}$ To be clear, voting stations and machines correspond to the same level of analysis.

${ }^{13}$ Not all voting machines contained ballots cast for our five outcome variables, hence the varying number of observations across our models.

${ }^{14}$ While there were 13 candidates competing in the first round of elections, the total vote shares of the first three contenders corresponded to 87.78 per cent of the total valid votes. Furthermore, if no candidate attains 50 per cent (plus one) of the votes, only two contenders move onto the second round. This means that the first three contenders are the ones effectively competing for a straight win in the first round or one of the two spots in the second round. As such, we restrict our analyses to the three most competitive candidates.
} 
Official data also include the time of actual closure of each voting machine (that is, when the last vote was cast). This allows us to identify which voting machines remained open after electoral results started being announced. Using this information, we identify our treatment and control units: machines that remained open after preliminary results started being announced (at 19:00 BRT) are considered to be treated and assigned a value of 1; machines that closed before 19:00 BRT are in our control group and assigned a value of 0 . In the first round, a total of 8,548 (1.6 per cent) observations are in our treatment group. After significant delays in the first round, the electoral authorities sought to address problems with the implementation of the biometric system, so the number of units that were exposed to information dropped substantially. In the second round, 1,084 (0.24 per cent) of voting machines were treated.

As illustrated in Figure 1 and Online Appendix C, technical glitches associated with the implementation of the biometric system increased the likelihood of information exposure in both rounds. In other words, exposure to electoral results overwhelmingly occurred in places where higher shares of voters had been registered to use the biometric system. As shown in Online Appendix B, Brazilian electoral authorities did not introduce the biometric system across the entire country at once. In the 2018 elections, higher shares of voters from the North and North-east had been registered to use the system. By definition, the uneven adoption of the system throughout the country means that treated and untreated units are dissimilar across characteristics of the electorate: the North and North-east are the poorest regions of the country, and the electorate in these regions are younger and less educated than in other regions.

However, this does not invalidate our identification strategy because the probability of occurrence of technical glitches was presumably the same in all voting stations using the biometric system. ${ }^{15}$ In sum, there is no reason to believe that the occurrence of technical glitches is associated with attributes of the electorate. As we show in the baseline models in Online Appendix D, pretreatment controls for characteristics of the electorate do not change our estimates.

\section{Identification}

Using the previously described data, we estimate whether late voters' access to information about early voters' preferences affected their voting behaviour in each round of the elections. We estimate Ordinary Least Squares (OLS) models for each outcome variable (that is, frontrunner, second place, third place, blank and null) following the general specification:

$$
Y_{i g}=\beta_{0}+\beta_{1} \text { Treatment }_{i g}+W_{i g}+\epsilon_{i g}
$$

The dependent variable is $Y$, and the subscript ${ }_{i}$ indicates that this varies across voting machines. Following the approach formulated by Abadie et al. (2017), gdenotes that standard errors are clustered at the level of voting machines, where technical glitches occurred. Treatment is a dummy that takes a value of 1 for voting machines that closed after the results started being released at 19:00 BRT (that is, the treatment group), and 0 for voting machines not affected by the release of information at 19:00 BRT (that is, the control group).

Our models also include a vector of covariates, as represented by $W_{i}$ in equation 1 . Voting conditions may change over time for all units, regardless of whether or not they are treated. To account for this, we control for the timing of closure of voting machines with the variable closure delay (in minutes). There are also other factors that could be associated with the likelihood

\footnotetext{
${ }^{15}$ Election procedures in Brazil are centralized, led and regulated by national-level authorities, and systematically implemented throughout the country. This means that the type of biometric machines employed and the training given to election staff on how to operate the machines were also systematically adopted throughout the country. For example, all election staff were trained to attempt reading an individual's fingerprint four times before using another form of ID to identify them. In other words, there is no indication that exposure to information in some units resulted from something other than technical glitches.
} 
of information exposure, so we control for the share of voters that faced technical issues when attempting to use the biometric system (\% error in biometrics) and the time zone of the machine's location.

Although it is not possible for information exposure to change voter behaviour through an increase in turnout rates (since voters arriving at their stations after the time of information exposure, that is, stations' closing times, would have been barred from entering), exposure to electoral results could still depress turnout, so it is possible that turnout rates are associated with changes in candidates' vote shares. To address this, we also control for turnout rates. ${ }^{16}$

Finally, characteristics of the electorate could also affect voter behaviour, so we additionally control for the characteristics of voters registered to cast ballots on each voting machine, specifically, average age, incidence of women voters ${ }^{17}$ and average years of schooling. Descriptive statistics for all variables are available in Online Appendix E.

\section{Results}

We begin by analysing the impact of information exposure on the first round of elections, when there are more than two candidates. Figure 2 summarizes our findings (for the table of results, see Online Appendix F).

The positive and statistically significant treatment effect produced by Model 1 already hints that information exposure does not affect voters through the demobilization of disillusioned voters (H1). Results from Models 4-5 are mixed: although the treatment effect produced by Model 4 is positive and statistically significant, it is substantively small, indicating a negligible increase of $0.31 \mathrm{pp}$ of blank votes in treated units. Conversely, the treatment effect produced by Model 5 is statistically significant but negative (the opposite of what this mechanism anticipates), indicating a decrease of $0.73 \mathrm{pp}$ in the share of null votes in treated units. If anything, results from Model 5 suggest that information exposure might have led individuals planning on casting invalid ballots to vote for the frontrunner instead. Together, our models provide weak support for $\mathrm{H} 1$ and suggest that information exposure does not benefit the frontrunner through demobilization.

Instead, our results provide stronger support for bandwagon conversion (H2): in addition to our finding that support for the announced frontrunner is $5.69 \mathrm{pp}$ higher in treated units (Model 1), the treatment effects that emerge from Models 2 and 3 also indicate that information exposure led to a decrease in support for losing candidates. More specifically, we find that the rates of support for the second- and third-place candidates are, respectively, $7.41 \mathrm{pp}$ and $1.97 \mathrm{pp}$ lower in treated units. Taken together, our estimates indicate that when influenced by information about the electoral results, some voters abandoned their preferred choices of a losing candidate and switched their votes to the predicted winner.

Substantively, these results translate into an average increase of 14 per cent in the vote share of Bolsonaro in treated units and an average loss of 26 per cent and 18 per cent in the respective vote shares of Haddad (second place) and Gomes (third place). ${ }^{18}$ To ensure the integrity of elections, voting machines shuffle the order of individual votes. This means that while there is a timestamp to register when each machine is closed (which we use to derive our treatment), it is not possible to know how many voters cast ballots after the threshold of information exposure. In other words, we cannot provide precise estimations for the number of votes Bolsonaro gained and Haddad and

\footnotetext{
${ }^{16}$ This is calculated by dividing the number of voters who turned up to vote on a given voting machine by the total number of voters registered to vote on the same voting machine.

${ }^{17}$ This is an indicator that varies between 2 and 4 . Values closer to 4 indicate a higher incidence of women registered to vote on a given voting machine.

${ }^{18} \mathrm{We}$ use the standard formula of percentage growth to estimate these effects. For example, in the first round, an average voting machine contained 41.12 votes for Bolsonaro (starting value). As per Model 1, the estimated effect of information exposure is $5.7 \mathrm{pp}$. We use these values in the standard formula of percentage growth by dividing the estimated effect by the starting value: $5.69 / 41.12=0.138 \times 100=13.83$, or roughly 14 per cent.
} 

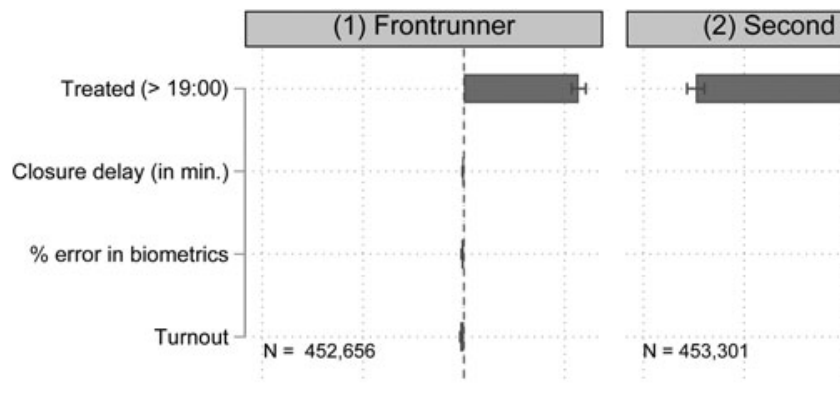

(3) Third place

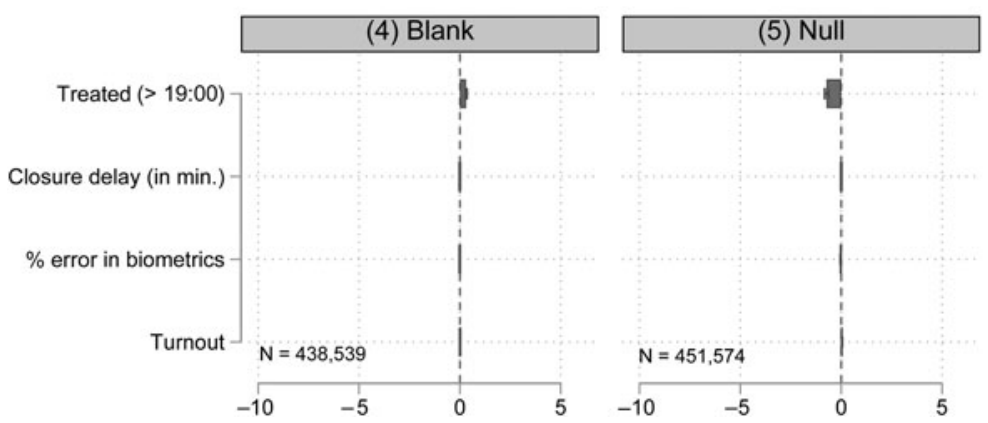

Fig. 2. The effect of information exposure on voting behaviour (first round).

Notes: The unit of analysis is voting machine. We cluster standard errors at the level of voting machine (where the treatment occurred). We run all OLS estimates with controls for time zone, age (avg.), percentage of women voters and years of schooling (avg.).

Gomes lost due to information exposure. Nonetheless, in Online Appendixes G-I, we provide estimations for a range of possible substantive effects.

In addition, the negative coefficient produced by Model 3 further indicates that we can reject the hypotheses of both mobilization-driven $(\mathrm{H} 3)$ and vote-switching underdog effects (H4). In other words, information exposure does not seem to lead to an aggregate-level underdog effect in favour of the trailing candidate.

While coefficients across our models provide more cohesive support for $\mathrm{H} 2$, our analyses cannot fully reject the possibility that information exposure prompts strategic voting (H5), as our findings are still consistent with a scenario in which a conversion bandwagon effect (H2) and strategic voting (H5) are simultaneously taking place, that is, where: (1) Gomes's supporters whose less-preferred candidate was Haddad switched votes to Bolsonaro; and (2) would-have-been supporters of Haddad jumped on to the bandwagon of the predicted winner and switched support for Bolsonaro. Even in this scenario, however, strategic voting alone could not explain our results; rather, vote switching among Haddad supporters would still have to be operating. In sum, while we cannot fully reject $\mathrm{H} 5$ at this stage of the analysis, we can attest that our findings are, at least in part, driven by a vote-switching bandwagon effect $(\mathrm{H} 2)$. To rule out the possibility that the frontrunner's advantage (and contenders' electoral loss) emerges from strategic voting, we next examine whether information exposure impacted voting behaviour in the second round of the elections, when the number of candidates is reduced to two and strategic voting is not possible.

\section{Is it Really a Bandwagon Effect? Examining Information Exposure in the Second Round of Elections}

Vote switching should be particularly unlikely in a highly polarized election with only two opposing candidates. If results from Figure 2 are the product of strategic voting, we should not observe a 
bandwagon effect in our analyses of the second round. However, given Bolsonaro's lead at the time of announcement of second-round vote tallies, if a vote-switching bandwagon effect $(\mathrm{H} 2)$ is indeed in place, we should observe an increase in the vote share of Bolsonaro among the treated units, a decrease in the vote share of Haddad and no changes in the shares of blank and null ballots.

This is precisely what we find. As Figure 3 shows (for the table of results, see also Online Appendix F), when only two candidates compete for the final electoral outcome, information exposure still drives high levels of support to the frontrunner. As indicated by the treatment effect produced by Model 1, Bolsonaro's vote share increases by $11.76 \mathrm{pp}$ in voting machines where voters were exposed to information.

Similarly to our previous findings, our analyses of voting behaviour in the second round suggest that the frontrunner's gained advantage is accompanied by a decrease of $12.14 \mathrm{pp}$ in the vote share of the losing candidate in treated voting machines. As before, the impact of information exposure on mobilization rates is mixed and substantively small: the share of blank ballots is $0.62 \mathrm{pp}$ higher, but the share of null votes is $0.44 \mathrm{pp}$ lower, in treated units.

These results indicate that information exposure benefits the frontrunner not because of strategic voting (H5), but through a bandwagon effect - more specifically, vote switching away from the predicted loser and in favour of the frontrunner (H2). Substantively, our results translate into an estimated gain of 24 per cent of support for Bolsonaro (frontrunner) in treated units and a loss of 28 per cent for Haddad (second place). Online Appendixes G-H provide additional analyses of estimated substantive effects.

\section{Robustness Checks}

Our results also remain stable in a series of robustness checks. First, in natural experiments, it is possible that certain observations may be in a position to always receive the treatment or to have a zero probability of being in the control condition (Titiunik 2021). Due to time-zone differences, voting machines located in the state of Acre officially close at 19:00 BRT, which corresponds to our threshold for information exposure. As such, even minor voting delays in Acre would necessarily place Acre-based voting machines in the treatment condition. In Online Appendix J, we rerun our estimates without Acre-based observations and find results that are consistent with those summarized in Figures 2 and 3.

Secondly, 41 per cent of the electorate was not registered to use biometrics as a form of voter ID, so not all voting machines were exposed to an increased probability of closing with delays (and, thus, information exposure). To address this, we also rerun our estimates on a restricted sample of observations where at least one instance of a biometrics-related technical glitch was recorded. As shown in Online Appendix K, our results are also robust to this test.

It is also possible that the effect of information exposure is heterogeneous and affects smaller and larger voting stations differently. If this is the case, our results could be driven by changes in voting behaviour in one type of voting station. In Online Appendix L, we test for this by producing separate models for voting machines with 0-220 registered voters (25th percentile), 220-339 registered voters (50th percentile) and more than 339 registered voters (75th percentile). Results across these models are largely consistent with the ones from our main estimates. The only difference comes from our analyses of the first round of elections when restricted to the smallest stations. In this context, exposure to electoral results still produced an increase in the vote share of Bolsonaro (first place) and a decrease in the vote share of Haddad (second place), but it also seems to have increased voter support for Gomes, the third-place candidate.

Finally, it is also possible that voters in treated units were already more prone to supporting the frontrunner, Bolsonaro, than voters in untreated units. Polls of voting intentions are not available at the level of voting machines, preventing us from conducting a direct analysis. We do the next 


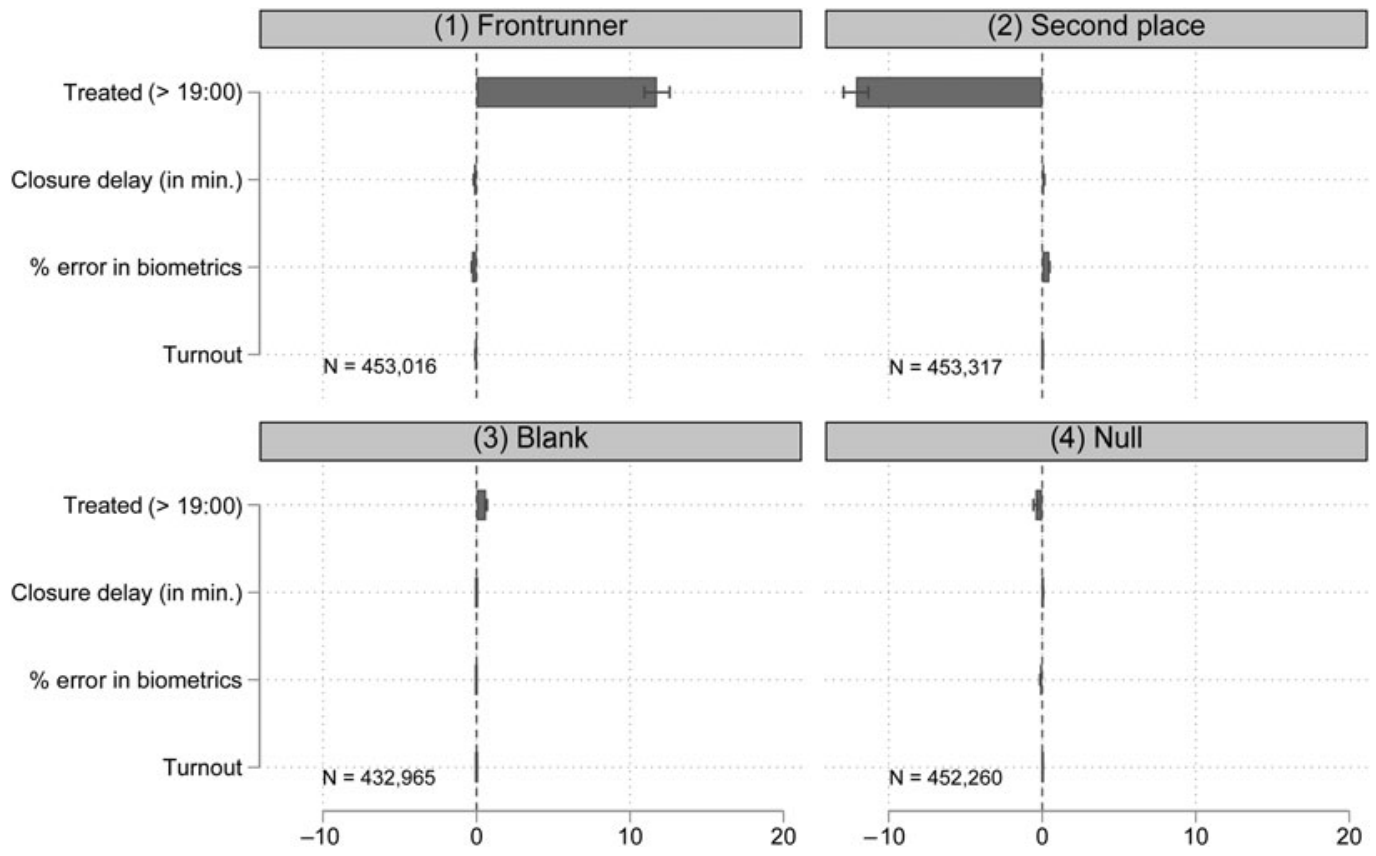

Fig. 3. The effect of information exposure on voting behaviour (second round).

Notes: The unit of analysis is voting machine. We cluster standard errors at the level of voting machine (where the treatment occurred). We run all OLS estimates with controls for time zone, age (avg.), percentage of women voters and years of schooling (avg.).

best thing and examine the electoral preferences of treated and untreated units in the 2014 presidential elections. Before 2018, neither Bolsonaro nor his party had ever run for the presidency. However, the centre-left PT - the party of the second-place candidate, Haddad - was one of the main contenders. The PSDB, a centre-right party, was its main competitor. If units treated in 2018 were more prone to supporting the far-right frontrunner, we would expect them to have displayed disfavour towards the centre-left PT and a preference for the centre-right PSDB in 2014.

As shown in Online Appendix M, when we replicate our 2018 estimates with 2014 data, this is the opposite of what we find. In fact, units exposed to information in 2018 were more prone to support the left-wing PT and less supportive of the centre-right PSDB. In other words, there is no evidence to suggest that units treated in 2018 were already more predisposed to supporting Bolsonaro; instead, their past electoral behaviour suggests that they would be, on average, more opposed to switching votes to a far-right candidate than other units.

In sum, across model specifications we find consistent evidence that information exposure results in a vote-switching bandwagon effect $(\mathrm{H} 2)$. However, by assigning treatment status to voting machines that remained open after official electoral results started being announced, our empirical strategy captures the impact of information exposure indirectly. In a real-world setting, it is virtually impossible to know whether the release of vote tallies indeed meant that individual voters saw this information before casting their ballots - and, thus, that it was knowledge of electoral results that shaped their behaviour. For example, it is possible that it was not knowledge of results, but voters' experiences of waiting in queue, that led late voters to behave differently from early voters. As Bolsonaro ran as an anti-system candidate (Hunter and Power 2019; Rennó 2020), having an unpleasant voting experience could have also led voters to punish 'insider' candidates that they more closely associated with state capacity and election logistics. We address this next. 


\section{Examining Non-information Exposure Through Placebo Tests}

To ensure that our results emerge from gaining knowledge of results and not another mechanism related to voters' experience of waiting in queue, we run additional robustness checks with a placebo treatment. To be considered treated units in our placebo analyses, voting machines would have had to close with a delay (after 17:00 local time) but before the announcement of electoral results (19:00 BRT). In other words, for these analyses, treated units encompass voting machines where voters faced delays and stayed in the queue but could not have been exposed to information.

Figure 4 summarizes our results for the first round of elections. As indicated by the direction of estimated effects, our placebo treatment shows no indication of a bandwagon effect. In fact, the direction of treatment effects in all models is opposite to what we would expect from a bandwagon effect: the frontrunner's vote share is decreasing before information exposure and the support for his contenders is increasing. We also find that our placebo treatment is associated with an increase in the share of null votes. This indicates that while waiting in queue does not lead voters to support the anti-system frontrunner (as indicated by Model 1), it potentially increases their tendency to cast protest ballots.

Estimates for the second round of elections confirm that the observable bandwagon effect does not emerge when voters face delays that do not surpass the threshold of information exposure (see Online Appendix N). As before, we also find that that the placebo treatment is associated with a decrease in the vote share of the frontrunner and an increase in the vote share of the losing candidate in the second round. Also similarly to our placebo analyses of the first round, in our second-round analyses, the placebo treatment is associated with increases in the share of protest ballots (that is, blank and null votes).

In sum, our placebo tests of the two rounds of election indicate that a bandwagon effect only emerges when the treatment corresponds to units that faced delays past the time threshold of information exposure. These results provide further indication that our treatment indeed captures access to information and that a vote-switching bandwagon effect only occurs when late voters gain knowledge of early voters' electoral preferences.

\section{Conclusion}

Does having access to information about candidates' electoral prospects before casting ballots impact voters' behaviour? While the literature examining the impact of information exposure on voter behaviour is vast, the context of naturally occurring elections has imposed key methodological challenges to tackling this question in a real-world setting, rendering scholars to widely rely on laboratory and survey experiments. Taking advantage of the unique conditions of the 2018 Brazilian presidential elections and of granular electoral data, we provide the first assessment of the impact of exposure to electoral results on the behaviour of voters in a single, real-world election.

In addition to improving causal estimation strategies while maintaining high external validity, the Brazilian institutional set-up of run-off elections also offers us the opportunity of going beyond equifinality and distinguishing between different mechanisms through which information exposure could impact voter behaviour. Employing a variety of model specifications from two rounds of elections, we consistently find that access to information about candidates' performances with early voters considerably impacts the behaviour of late voters. Specifically, our results indicate that information exposure encourages late voters to abandon their preferred but losing candidates in favour of the predicted winner. Results from additional analyses reinforce the notion that information exposure and vote switching are indeed what yield the observed bandwagon effect: in analyses of second-round results, when strategic voting is not possible, we still observe vote switching in favour of the frontrunner; while in placebo tests, we find that a bandwagon effect does not emerge in delayed but non-exposed voting machines. 


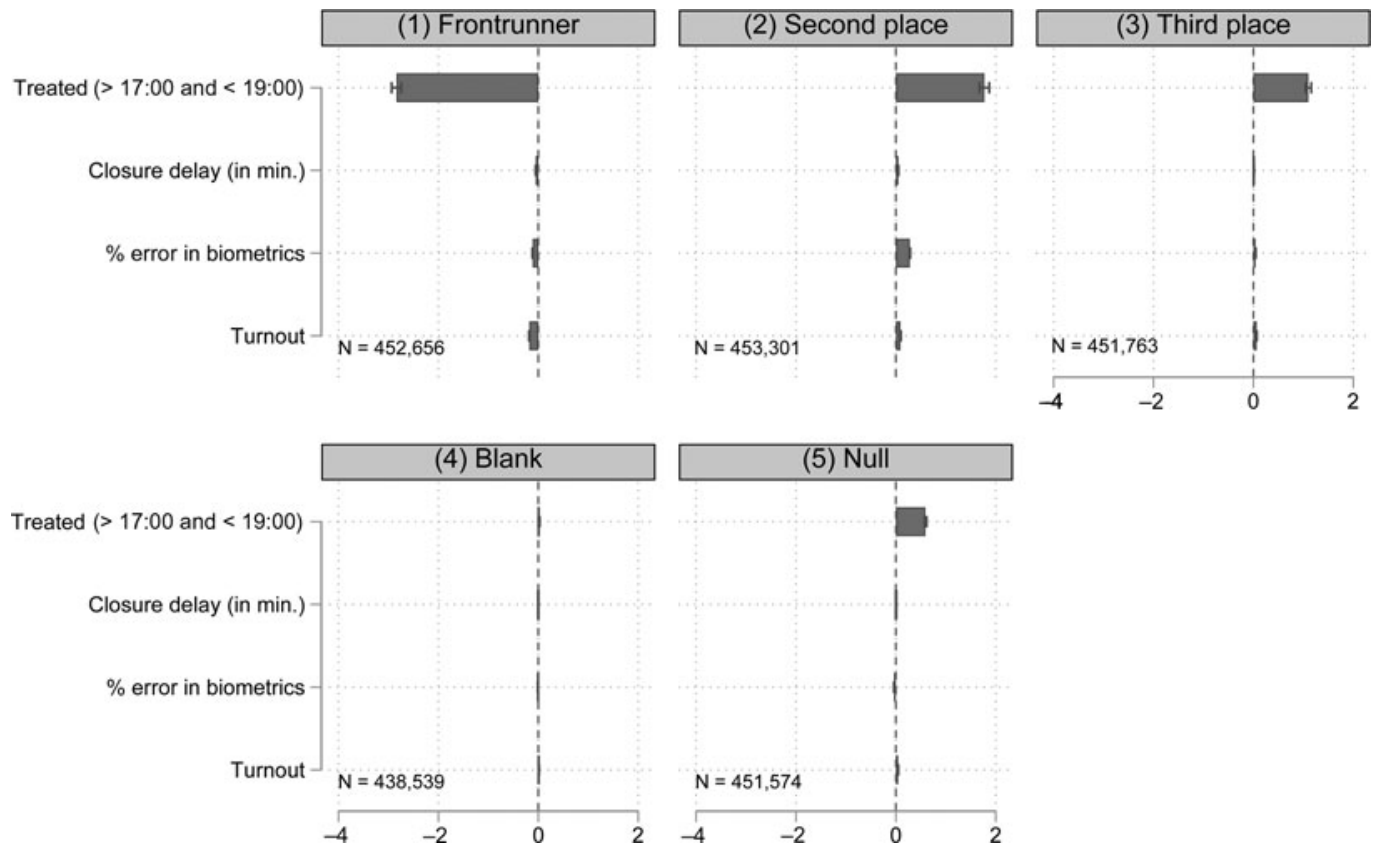

Fig. 4. The effect of non-information exposure on voting behaviour - placebo treatment (first round). Notes: The unit of analysis is voting machine. We cluster standard errors at the level of voting machine (where the treatment occurred). We run all OLS estimates with controls for time zone, age (avg.), percentage of women voters and years of schooling (avg.).

Our findings have significant institutional and normative implications. First, our results indicate that the implementation of a new form of voter ID inadvertently exposed voters to information that influenced their behaviour. Although the total number of votes gained and lost as a result of information exposure did not change electoral outcomes, this is only the case because Brazilian electoral technologies and institutions are highly efficient: despite the glitches, the number of voting machines that remained open after vote tallies started being announced would not be sufficient to alter electoral results at the national level. Nonetheless, as Morton et al. (2015) and Morton and $\mathrm{Ou}$ (2015) have argued, the effects of sequential voting on electoral behaviour should be increasingly discussed, especially given that many institutional and technological innovations advocated for facilitating voter participation (for example, convenience voting) could also increase the likelihood of information diffusion while elections are still taking place.

Secondly, there are normative implications to consider. Exposure to information gives early voters' preferences greater weight in elections, but democratic electoral processes are rooted in the notion that every vote counts equally (Thompson 2004). This means that discussions about the potential consequences of information exposure are a matter of electoral integrity.

Our findings also open possibilities for future scholarship. Unlike much of the literature on bandwagon effects, our results emerge from a situation of exposure to vote tallies, not preelectoral polls. As such, it is possible that the size of effects and dynamics uncovered here are also shaped by levels of trust and a sense of urgency when confronted with information from actual results. This points to the need to consider the type of information to which voters are exposed.

Previous scholarship from elsewhere suggests that the effects we uncover here are not unique to Brazil and are likely to emerge in different types of political systems and contexts, including Britain (McAllister and Studlar 1991), France (Morton et al. 2015), India (Chatterjee and Kamal 2020) and Israel (Riambau 2015). However, as we show, there are also characteristics 
that are specific to the Brazilian context, such as, for example, the impossibility of a bandwagon effect emerging from higher rates of turnout. Future works should continue to consider the ways in which institutional set-ups may condition the potential impacts of information exposure on voter behaviour.

Supplementary Material. Online appendices are available at https://doi.org/10.1017/S000712342100034X

Data Availability Statement. Replication data for this article can be found in Harvard Dataverse at: https:/doi.org/10.7910/ DVN/GD92NS

Acknowledgements. We dedicate this article to Rebecca Morton (in memoriam), a pioneer in the study of voter behaviour in sequential elections and whose work served as an inspiration to a generation of political scientists. We are thankful to three anonymous reviewers and editor Robert Johns, as well as to Acir Almeida, K. Maja Birchler, Néstor Castañeda, Paula Castro, David Doyle, Sarah Engler, Florian Foos, Kai Gehring, Fabrizio Gilardi, Maurício Izumi, Philipp Kerler, Fernando Limongi, Katharina Michaelowa, Patrícia Nabuco, Timothy Power, Thiago Silva, Martina Zahno and Cesar Zucco Jr, for their helpful comments and suggestions. We also benefited from helpful questions and feedback from participants of seminars at King's College London, the London School of Economics and the University of Zurich. All remaining errors are our entire responsibility.

Author contributions. Authors' names are listed in alphabetical order.

\section{References}

Abadie A et al. (2017) When Should You Adjust Standard Errors for Clustering? Technical Report. Boston, MA: National Bureau of Economic Research.

Agranov M et al. (2018) What makes voters turn out: the effects of polls and beliefs. Journal of the European Economic Association 16(3), 825-856. Available from https://academic.oup.com/jeea/article/16/3/825/4061429

Araújo V and Gatto MAC (2021) Replication Data for: 'Casting ballots when knowing results', https://doi.org/10.7910/DVN/ GD92NS, Harvard Dataverse, V1, UNF:6:gXogVjQYsdX4GB/2b9vpAg== [fileUNF].

Alvarez RM and Nagler J (2000) A new approach for modelling strategic voting in multiparty elections. British Journal of Political Science 30(1), 57-75.

Barnfield M (2019) Think twice before jumping on the bandwagon: clarifying concepts in research on the bandwagon effect. Political Studies Review 18(4), 553-574.

Bartels LM (1988) Presidential Primaries and the Dynamics of Public Choice. Princeton, NJ: Princeton University Press.

Bischof D (2017) New graphic schemes for Stata: plotplain and plottig. The Stata Journal 17(3), 748-759.

Bischoff I and Egbert H (2013) Social information and bandwagon behavior in voting: an economic experiment. Journal of Economic Psychology 34, 270-284.

Blais A et al. (2011) Strategic vote choice in one-round and two-round elections: an experimental study. Political Research Quarterly 64(3), 637-645. Available from https://doi.org/10.1177/1065912909358583

Carpini MXD (1984) Scooping the voters? The consequences of the networks' early call of the 1980 presidential race. The Journal of Politics 46(3), 866-885. Available from https://doi.org/10.2307/2130859

Cepaluni G and Hidalgo FD (2016) Compulsory voting can increase political inequality: evidence from Brazil. Political Analysis 24(2), 273-280.

Chatterjee S and Kamal J (2020) Voting for the underdog or jumping on the bandwagon? Evidence from India's exit poll ban. Public Choice 188, 431-453.

Chung S, Heo Y-J and Moon J-H (2018) Perceived versus actual polling effects: biases in perceptions of election poll effects on candidate evaluations. International Journal of Public Opinion Research 30(3), 420-442.

Clavery E (2018) Cadastro de biometria detecta 25mil títulos de eleitor duplicados. Exame. Available from https://exame. $\mathrm{com} /$ brasil/cadastro-de-biometria-detecta-25mil-titulos-de-eleitor-duplicados/

Cox GW (1997) Making Votes Count: Strategic Coordination in the World's Electoral Systems. New York, NY: Cambridge University Press. Available from https://doi.org/10.1017/s0048840200025132

Downs A (1957) An economic theory of political action in a democracy. Journal of Political Economy 65(2), 135-150.

Dubois PL (1983) Election night projections and voter turnout in the West: a note on the hazards of aggregate data analysis. American Politics Quarterly 11(3), 349-364. Available from https://doi.org/10.1177/004478083011003005

Duffy J and Tavits M (2008) Beliefs and voting decisions: a test of the pivotal voter model. American Journal of Political Science 52(3), 603-618. Available from http://doi.wiley.com/10.1111/j.1540-5907.2008.00332.x

Duverger M (1954) Political Parties: Their Organization and Activity in the Modern State. London, UK: Methuen.

Eggers AC and Vivyan N (2020) Who votes more strategically? American Political Science Review 114(2), 470-485.

Evrenk H and Sher C-Y (2015) Social interactions in voting behavior: distinguishing between strategic voting and the bandwagon effect. Public Choice 162(3-4), 405-423. 
Farjam M (2020) The bandwagon effect in an online voting experiment with real political organizations. International Journal of Public Opinion Research 33(2), 412-421.

Fleitas DW (1971) Bandwagon and underdog effects in minimal-information elections. American Political Science Review 65 (2), 434-438. Available from https://www.cambridge.org/core/product/identifier/S0003055400134665/type/journal_article

Fujiwara T (2011) A regression discontinuity test of strategic voting and Duverger's law. Quarterly Journal of Political Science 6(3-4), 197-233. Available from https://doi.org/10.1561/100.00010037

G1 (2018) Jair Bolsonaro é eleito presidente com 57,8 milhões de votos. Available from https:/g1.globo.com/politica/eleicoes/ 2018/apuracao/presidente.ghtml

Gallup G and Rae SF (1940) Is there a bandwagon vote? Public Opinion Quarterly 4(2), 244-249.

Gartner M (1976) Endogenous bandwagon and underdog effects in a rational choice model. Public Choice 25(1), 83-89. Available from http://link.springer.com/10.1007/BF01726338

Grandin F et al. (2018) Bolsonaro chegou a ter 62 per cent dos votos válidos durante a apuração; Haddad liderou por 10 minutos. G1. Available from https:/g1.globo.com/politica/eleicoes/2018/eleicao-em-numeros/noticia/2018/11/01/bolsonaro-chegou-a-ter-62-dos-votos-validos-durante-a-apuracao-haddad-liderou-por-10-minutos.ghtml

Grillo A (2017) Risk aversion and bandwagon effect in the pivotal voter model. Public Choice 172(3-4), 465-482.

Großer J and Schram A (2010) Public opinion polls, voter turnout, and welfare: an experimental study. American Journal of Political Science 54(3), 700-717. Available from http://doi.wiley.com/10.1111/j.1540-5907.2010.00455.x

Guarnieri F (2015) Voto estratégico e coordenação eleitoral testando a Lei de Duverger no Brasil. Revista Brasileira de Ciências Sociais 30(89), 77-92.

Hardmeier S (2008) The effects of published polls on citizens. In Donsbach W and Traugott MW (eds) The SAGE Handbook of Public Opinion Research, London, UK: Sage, vol. 1, pp. 504-513.

Heath A and Evans G (1994) Tactical voting: concepts, measurement and findings. British Journal of Political Science 24(4), $557-561$.

Hunter W and Power TJ (2019) Bolsonaro and Brazil's illiberal backlash. Journal of Democracy 30(1), 68-82. Available from https://www.journalofdemocracy.org/articles/bolsonaro-and-brazils-illiberal-backlash/

Hutt R (2018) These are the countries with the highest voter turnout. World Economic Forum. Available from https://www. weforum.org/agenda/2018/11/these-countries-have-some-of-the-highest-voter-turnout-in-the-world/

Kawai K and Watanabe Y (2013) Inferring strategic voting. American Economic Review 103(2), 624-662.

Kenney PJ and Rice TW (1994) The psychology of political momentum. Political Research Quarterly 47(4), 923-938.

Levy JS (2008) Case studies: types, designs, and logics of inference. Conflict Management and Peace Science 25(1), 1-18.

Lopez B (2019) Brazil is the 5th country in smartphone usage. PagBrasil. Available from https://www.pagbrasil.com/insights/ smartphone-usage-in-brazil/

McAllister I and Studlar DT (1991) Bandwagon, underdog, or projection? Opinion polls and electoral choice in Britain, 1979-1987. The Journal of Politics 53(3), 720-741.

Mello PC (2020) A máquina do ódio: notas de uma repórter sobre fake news e violência digital. São Paulo, SP: Companhia das Letras.

Mendonça AV and Albernaz B (2018) Biometria 'de surpresa', urnas quebradas e filas de até $3 \mathrm{~h}$ marcam $1^{\circ}$ turno no RJ. October. Available from https://g1.globo.com/rj/rio-de-janeiro/eleicoes/2018/noticia/2018/10/07/biometria-de-surpresae-urnas-quebradas-formam-filas-em-secoes-no-rj.ghtml

Morton RB and Ou K (2015) What motivates bandwagon voting behavior: altruism or a desire to win? European Journal of Political Economy 40(December), 224-241. Available from https://www.sciencedirect.com/science/article/pii/ S0176268015000488

Morton RB and Williams KC (1999) Information asymmetries and simultaneous versus sequential voting. American Political Science Review 93(1), 51-67. Available from https://www.cambridge.org/core/product/identifier/S000305540021 6614/type/journal_article

Morton RB et al. (2015) Exit polls, turnout, and bandwagon voting: evidence from a natural experiment. European Economic Review 77, 65-81. Available from https://doi.org/10.1016/j.euroecorev.2015.03.012

Moy P and Rinke EM (2012) Attitudinal and behavioral consequences of published opinion polls. In Holtz-Bacha C and Strömbäck J (eds) Opinion Polls and the Media. London: Palgrave Macmillan UK, pp. 225-245. Available from http:/l link.springer.com/10.1057/9780230374959_11

Nicolau JM (2012) Eleições no Brasil: do Império aos dias atuais. São Paulo: Zahar.

Plutowski L, Weitz-Shapiro R and Winters MS (2020) Voter beliefs and strategic voting in two-round elections. Political Research Quarterly 0, 1-14.

Power TJ (2009) Compulsory for whom? Mandatory voting and electoral participation in Brazil, 1986-2006. Journal of Politics in Latin America 1(1), 97-122. Available from https://doi.org/10.1177/1866802×0900100105

Power TJ and Rodrigues-Silveira R (2019) Mapping ideological preferences in Brazilian elections, 1994-2018: a municipallevel study. Brazilian Political Science Review 13(1), 1-27. Available from http://www.scielo.br/scielo.php?script=sci arttext\&pid=S1981-38212019000100200\&lng=en\&tlng=en

Rennó LR (2020) The Bolsonaro voter: issue positions and vote choice in the 2018 Brazilian presidential elections. Latin American Politics and Society 62(3), 1-23. 
Riambau G (2015) Bandwagon or strategic voting in Israel? Note on Bargsted and Kedar 2009. Electoral Studies 37, 63-72. Samuels DJ and Zucco C Jr (2018) Partisans, Antipartisans, and Nonpartisans: Voting Behavior in Brazil. Cambridge, UK: Cambridge University Press.

Schmitt-Beck R (1996) Mass media, the electorate, and the bandwagon. A study of communication effects in Germany. International Journal of Public Opinion Research 8(3), 266-291. Available from https://academic.oup.com/ijpor/articlelookup/doi/10.1093/ijpor/8.3.266

Thompson DF (2004) Election time: normative implications of temporal properties of the electoral process in the United States. American Political Science Review 98(1), 51-64. Available from https://doi.org/10.1017/s0003055404000991

Titiunik R (2021) Natural experiments. In Druckman J and Green D (eds) Advances in Experimental Political Science. Cambridge: Cambridge University Press, pp. 103-129.

Zucco C Jr and Nicolau JM (2016) Trading old errors for new errors? The impact of electronic voting technology on party label votes in Brazil. Electoral Studies 43, 10-20. Available from https://doi.org/10.1016/j.electstud.2016.04.001

Cite this article: Araújo V, Gatto MAC (2021). Casting Ballots When Knowing Results. British Journal of Political Science 1-19. https://doi.org/10.1017/S000712342100034X 